doi: $10.1111 / 1753-6405.13048$

\section{The failure of health promotion for marginalised populations}

\author{
Michael Roguski, ${ }^{1}$ Karen McBride-Henry ${ }^{2}$ \\ 1. Kaitiaki Research and Evaluation, New Zealand \\ 2. Health Services Research Centre, Victoria University of Wellington, New Zealand
}

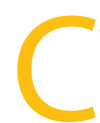
onventional approaches to health promotion often exclude our most marginalised populations. ${ }^{1}$ This can be traced to a lack of trust of those who are conveying the particular message or call to action, a lack of resonance with the prioritisation of the particular message, different cultural priorities and understandings of key issues, and - above all - a lack of self-determination surrounding the population's determinants of health. In this sense, the marginalised population lacks agency in identifying their own priorities and the various ways that such determinants might be addressed. This commentary draws on the lived realities of criminal gang members and their whānau (wider family) ${ }^{2}$ as a means of highlighting the need for us to think differently about our approaches to health promotion. It is noteworthy that this discussion is equally relevant to a host of populations that exist external to dominant western discourses.

\section{Understanding the divide}

Rather than a neutral discipline, health promotion is inherently political.' Further, Bernier and Clavier argue that "conceiving politically neutral policy improvements for better public health outcomes and reduced social health inequalities is a fiction we need to come to terms with".3(1114) The political nature of health promotion can be appreciated on myriad levels. At its most simple, the politics of health promotion rests on the discipline's definition that focuses on empowering individuals to have agency over, and the ability to improve, their health. ${ }^{4}$ Despite the individualised focus, in reality, health promotion predictably occurs through an authoritative body's strategic decision to focus on specific determinants of health. Within this frame, health promotion holds a paternalistic position. Within the Aotearoa
New Zealand (Aotearoa) context, decisions about health promotion activities are typically based on government decision making and have been heavily influenced by stakeholder groups. As such, specific health promotion foci, and concomitant strategies, have not been made solely on need. Rather, lobbyists have exerted considerable influence to ameliorate possibly 'drastic' changes required to reach the World Health Organization's goals for health promotion. ${ }^{4}$ This has been most acutely seen from the tobacco industry, which has had a substantial role tempering calls for a smoke-free nation. More recently, efforts to curb obesity have focused on a sugar tax, a strategy that has been heavily disputed by such groups as the New Zealand Food and Grocery Council. ${ }^{5}$

Further, the political nature of health promotion can be appreciated in light of the discipline's foundation as a western construction; a construction referred to by Mason Durie as 'generic' health promotion. ${ }^{6,7}$ Within this construction, health promotion reflects a discourse that implicitly serves the interests of the dominant population. Within Aotearoa, this means New Zealand Europeans $\mathrm{s}^{1,8}$ and, as a consequence, nullifies the nation's socio-cultural and colonial history.

The generic health promotion model has been critiqued because a host of significant health inequities exist. These are especially evident in relation to Māori, Indigenous people of Aotearoa, and the dominant population; inequities that parallel the experiences of Indigenous people in other nation states whereby Indigenous peoples are consistently over-represented in morbidity and mortality statistics..$^{9110}$ For example, an analysis conducted by Marriot and $\mathrm{Sim}^{11}$ found an averaged reduced life expectancy of more than seven years for
Māori males and females compared to non-Māori. Further, Māori have higher rates of a range of health and social indicators of wellbeing. These include higher rates of cigarette smoking, household crowding, and increasing incidence of diabetes, suicide and obesity. ${ }^{11}$ Importantly, these gaps can in part be attributed to socioeconomic factors, the most notable of which is an increasing divide between New Zealand European and Māori median household income. ${ }^{11}$

In addition, generic health promotion approaches have been critiqued because the marginalised other - for instance, Māori - occupy a social and economic space outside of the institutions and mechanisms of power and influence. The importance of a lack of social capital is important in that common readings of the generic model implicitly rely on a pluralist epistemological worldview. Based on a consensus view of society, classical pluralist theory posits that democracy is actualised, in part, through the dispersal of power across a variety of interest groups and it is the role of the state to act in the interests of wider society. ${ }^{1,12}$ However, the logic underlying this position is faulty as many marginalised populations do not have a societally endorsed organisational structure. As such, these populations are not positioned to advocate or lobby for change.

\section{Illustrating the challenge - criminal gangs in Aotearoa}

Historically, gangs in Aotearoa have been framed as the criminal and as the deviantised other with a host of anti-social indicators, such as incidences as family violence and imprisonment, having been used to justify this othered position. ${ }^{2}$ In response, gangs' criminally othered position has been reinforced by a combative discourse, denoted by varying levels of prevention, intervention and suppression strategies, that have sought to eradicate the perceived 'problem.' ${ }^{\prime 3,14}$ As an object of eradication, these strategies have continually nullified the voice and realities of the population in question.

Rather than employing a criminogenic epistemology, Roguski ${ }^{2}$ argues for the need to view gangs within their socio-historical realities. Within this worldview, the majority of adult gang development in Aotearoa can be understood to have developed as a consequence of colonisation, whereby 
Māori have been treated as expendable and attributed with a secondary societal status. ${ }^{15}$ It is widely acknowledged that many of the gangs in Aotearoa have an overrepresentation of Māori membership. ${ }^{13}$

Expendability is evidenced in periods of economic development, whereby large numbers of Māori have moved to urban centres in search of employment, and generally settled in low-income city areas. ${ }^{16}$ Such 'development' coincided with the emergence of the state's removal of children identified 'at risk' and the placement of these children in state care, whether foster care or within correctional settings. ${ }^{17}$

Consequently, rather than identities derived from culture or biological family structures, these young people formed identities in relation to metaphorical family structures $-\mathrm{a}$ brotherhood, if you will. These identities were unified by a history of state care, criminalised labelling, social exclusion and a resistance to authority. It was within this context that the Black Power and Mongrel Mob developed, classed as Māori and Polynesian ethnic gangs by the 1981 Committee on Gangs. ${ }^{18}$

The criminogenic framing of gangs has been reinforced through episodes of negative societal labelling that have resulted in the continued marginalisation of gang members and their whānau. Continued marginalisation led to reinforcing cycles of social exclusion; these cycles provided a context for criminal offending and the entrenchment of a number of negative social and economic indicators. ${ }^{2}$ As a result, many gang members, and their whānau, have developed constructions of self that are embedded within a socially marginalised space; a space created by exclusionary processes and necessity. On one hand, these identities have been forced upon gang whānau as a result of dominant criminogenic constructions. However, whānau have often understandably embraced a marginalised space as it provides a sense of safety - social exclusion effectively means the whānau exists outside of state and public surveillance. Within this marginalised space, and associated context, government and community organisations are treated with caution. ${ }^{2}$

\section{Health promotion and gang whānau}

An appreciation of dominant health promotion discourse, in relation to these marginalised whānau, highlight areas where health promotion models, and the inherent assumptions, fail to meet the needs and aspirations of an oft-ignored section of society. If it can be accepted that the primary position of gang whānau is one of societal isolation and marginalisation, it is useful to juxtapose the whānau position against the way in which health promotion is generally undertaken in Aotearoa; the aim of which is to highlight areas in which health promotion activity and assumptions fall short.

Positively, the Ottawa Charter provides a sufficiently broad definition of health to encompass a holistic conceptualisation of health: "Health promotion is the process of enabling people to increase control over, and to improve, their health. To reach a state of complete physical, mental and social well-being, an individual or group must be able to identify and to realize aspirations, to satisfy needs, and to change or cope with the environment".4p2) However, the way in which health promotion is realised through the various roles forwarded by the Charter generally assumes that health promotion is an actor-assisted process, external to the population in question. For instance, the Charter outlines three basic prerequisites that have evolved to be understood as health promotion roles - that is, the role of the advocate, enabler and mediator ${ }^{19}$ - roles that have commonly manifested through the efforts of health promoters, public health experts and policy makers. However, these roles are incongruent with the lived realities; namely, social exclusion experienced by gang whānau, whereby resistance and suspicion of a third-party actor, acting in a health promotion role, is perceived to be someone aligned with state authority (for additional information please see Roguski²).

An added incompatibility are the various strategies outlined in the Charter. Again, these strategies currently exist outside of whānau realities. Strategies of developing public health policy, creating supportive environments, strengthening community action, fostering the development of personal skills and reorienting health services have not been able to address the needs of marginalised whānau. This is a direct result of their relative invisibility, the reliance on a criminogenic rather than health discourse and whānau distrust of external influences. ${ }^{4}$

A growing number of Indigenous peoples have attempted to ensure that health-related discourses are relevant, as well as culturally responsive and appropriate, through the development of a variety of models that reflect specific cultural frameworks. From a Pacific peoples' standpoint, Tu'tahi and Lima further that the Ottawa Charter provides a framework for health promotion but that health promotion "must consider Pacific peoples' distinctive values, notions of health and wellbeing, and preferred approaches."2(p74) Within the context of Aotearoa, Māori academics have stressed the importance of locating health promotion within Māori worldviews with a particular emphasis on Māori self-determination. ${ }^{7,21}$

One challenge arising from culture-specific frameworks is founded in an essentialist conceptualisation, which assumes ethnicity and cultural identity naturally co-occur. However, the lived realities of the whānau in question reflects a history of social exclusion, state intervention and separation from biological whānau that has resulted in a dislocation from extended whānau structures, namely whānau, hapū (subtribe) and iwi (tribe). Such separation has been commonly exacerbated by either a lack of knowledge of one's whakapapa (genealogy) or as a result of the gang whānau being viewed as 'criminal others'. In this sense, an assumption cannot be made that gang whānau will either regard their relevant hapū and iwi as authoritative structures, or that the hapū and iwi would automatically want to include the gang whānau in their various initiatives. As such, an assumption that a Māori model of health promotion is the most appropriate approach needs to be problematised because of an assumed essentialist categorisation.

A second challenge is that the Indigenous health promotion models exist within a parallel hegemonic discourse. While the models have forwarded key cultural understandings, they have not offered a radically alternative framework to the generic model of health promotion. This can be most acutely appreciated when considering the following positioning of Mãori health promotion in relation to generic approaches:

There is little difference between generic health promotion among Māoriand generic health promotion among other population groups, regardless of who is delivering it. That is, a general formula is adapted to be appropriate to Māori in the same way, for example, that it is adapted to be appropriate to teenagers... The key distinction, however, is thelocus of control. Generichealth promotion carried out by a Māori workforce located within a mainstream organisation tends 
ultimately to be under the control of nonMāori. Māori health promotion is about self-determination; control of interventions should rest with Māori organisations [emphasis added]. ${ }^{7(p 59)}$

Such positioning fails to consider the needs and aspirations of gang whānau. A parallel hegemonic discourse exists in that Indigenous and generic models of health promotion implicitly rest on the authority of an informed body providing at least a modicum of guidance to the community in question to act as an advocate, enabler or mediator. Such an approach is problematic as the mechanisms of change and influence underpinning health promotion assume a relationship between the body wanting to influence change and the recipient body.

\section{Conclusion}

Addressing the needs of a specific marginalised population demands a novel approach, distinct from generic and Indigenous models of health promotion. To this end, lessons arising from our work with gang whānau provides a possible theoretical framework to support marginalised groups to address their own determinants of health. ${ }^{2}$

We posit three principles as essential to marginalised populations' health promotion. First, self-determination should be regarded as an overarching principle that provides the population in question with the freedom to direct the focus and the manner in which health promotion is developed and implemented. Second, processes in which the population can engage collectively are essential as it cannot be assumed that members possess sufficient levels of collective trust to work together to develop a shared vision. As such, the population needs time to develop its own engagement processes. For instance, in our research, gang whānau from different geographical areas were provided funding to allow them to meet as a collective to identify health issues and jointly discuss possible strategies. ${ }^{2}$ This meant all whānau could contribute to strategy development supporting a trust-based environment in which to work collectively. Finally, complementing community development theory, and in conflict with the desire to create quick and measurable health outcomes, it should be assumed that the collective might need to engage in activities as a means of developing individual and collective confidence, as well as awareness of health needs, before embarking on more conventional health promotion activities, for example smoking cessation. For gang whānau, collective engagement was acknowledged as a substantial outcome, and that in the process of meeting, over consecutive weeks, the whānau viewed these collective activities as 'baby steps' towards more significant health-based outcomes.

Notably, self-determination and engagement principles challenge the conventional role of third-party actors. In our research, third-party actors were absent from some of the gang whānau entirely; whereas, other whānau chose to enlist the support of a third party for specific training or planning activities. Importantly, when enlisted, third-party actors walked alongside and offered guidance when requested by the population. This contrasts with a third party who may venture in with predetermined health determinant objectives, and health promotion models, that do not reflect the lived realities of the population in question.

Lessons learned from engaging with gang whānau have applicability to a wide range of marginalised populations, as the population is afforded opportunities to determine their own health needs, associated strategies, and health promotion activities. Identifying those who are most marginalised cannot be treated as a prescriptive exercise. Rather, we need to be cognisant of populations with no, or limited, voice and who demonstrate a scepticism of third-party actors and the role of state interference. In Aotearoa, such populations may include transgender, intersex, and refugee and migrant populations.

In light of the social exclusion of highly marginalised populations, such as gang whānau, the need for shifts in power and resource structures challenge much of the accepted generic and Indigenous models of health promotion. The lived realities of many marginalised populations mean that it cannot be assumed that government, or an external organisation, have a health promotion role. This challenges conventional approaches that rely on a third party to identify health determinants and establish health promotional activities, as well as upending the role of health promotion practitioners.

\section{References}

1. Signal L, Jenkin G, Poata-Smith E. The politics of health promotion. In: Signal L, Ratima M, editors. Promoting Health in Aotearoa New Zealand. Dunedin (NZ): Otago University Press; 2015. p. 162-87.

2. Roguski M. Achieving wellbeing and prosocial transformation through social mobilisation: An evaluation of a gang empowerment strategy. Decolonization of Criminology and Justice. 2019;1(1):78105.

3. Bernier NF, Clavier C. Public health policy research: Making the case for a political science approach. Health Promot Int. 2011;26(1):109-16.

4. World Health Organization. The Ottawa Charter for Health Promotion. Geneva (CHE):WHO; 1986.

5. Thomas R. Sugar tax debate: How could we tax fizzy drinks? Stuff. 2016;Oct 11:18:55.

6. Durie M. An Indigenous model of health promotion Proceedings of the 18th World Conference on Health Promotion and Health Education; 2004 Oct 21-22; Melbourne, Australia.

7. Ratima M, Durie M, Hond R. Māori health promotion. In: Signal L, Ratima M, editors. Promoting Health in Aotearoa New Zealand. Dunedin (NZ): Otago University Press; 2015. p. 42-63.

8. Mulgan R. Politicsin NewZealand. 3rded. Auckland (NZ) Auckland University Press; 2004

9. Ajwani S, Blakely T, Robson B, Tobias M, Bonne M. Decades of Disparity: Ethnic Mortality Trends in New Zealand 1980-1999. Wellington (NZ): New Zealand Ministry of Health; 2003.

10. Bramley D, Hebert P, Tuzzio L, Chassin M. Disparities in Indigenous Health: A cross-country comparison between New Zealand and the United States. Am Public Health. 2005;95(5):844-50.

11. Marriot L, Sim D. Indicators of inequality for Māori and Pacific People. JNZStud. 2015;20:24-50.

12. Haywood T. A simple typology of internationalmindedness and its implications for education. In: Hayden M, Levey J, Thompson J, editors. The Sage Handbook of Research in International Education. London (UK): Sage Publications; 2007. p. 79-89.

13. Gilbert J. Patched: The History of Gangs in New Zealand. Auckland (NZ): Auckland University Press; 2013.

14. Maher J. Youth gang crime. In: Brookman F, Maguire $\mathrm{M}$, Pierpoint T, Bennet T, editors. Handbook on Crime. Devon (UK): Willan Publishing; 2010. p. 308-30.

15. Walker R. Ka Wahawhai Tonu Matou: Struggle Without End. Auckland (NZ): Penguin Publishers; 1990.

16. Quince K. Māori and the criminal justice system in New Zealand. In: Tolmie J, Brookbanks W, editors. Criminal Justice in NewZealand. Auckland (NZ): LexisNexis; 2007. p. 333-58.

17. Stanley E. The Road to Hell: State Violence against Children in Post-war New Zealand. Auckland (NZ): Auckland University Press; 2016

18. Comber K, Committee on Gangs. Report of the Committee on Gangs. Wellington (NZ): Government of New Zealand; 1981.

19. Signal L, Ratima M. Introduction. In: Signal L, Ratima $\mathrm{M}$, editors. Promoting Health in Aotearoa New Zealand. Dunedin (NZ): Otago University Press; 2015. p. 7-18.

20. Tu'itahi S, Lima I. Pacific health promotion. In: Signal L, Ratima M, editors. Promoting Health in Aotearoa New Zealand. Dunedin (NZ): Otago University Press; 2015. p. 64-81.

21. Durie M. Te Pae Mahutonga: A model for Mãori health promotion. Health Promot Forum NZNewsl. 1999;49:2-5.

Correspondence to: Dr Karen McBride-Henry،

Health Services Research Centre, Victoria

University of Wellington, PO Box 600 ,

Wellington 6140, New Zealand;

e-mail: karen.mcbride-henry@vuw.ac.nz 